\title{
Sensitive-stage embryo irradiation affects embryonic neuroblasts and adult motor function
}

\author{
Ram Wagle ${ }^{1}$ Young-Han Song ${ }^{1,2}$
}

Accepted: 16 December 2021 / Published online: 10 January 2022

(c) The Author(s) 2022

\begin{abstract}
Background Cranial radiation therapy for treating childhood malignancies in the central nervous system or accidental radiation exposure may result in neurological side effects in surviving adults. As tissue homeostasis is maintained by stem cells, understanding the effect of radiation on neural stem cells will provide clues for managing the neurological effects. Drosophila embryos were used as a model system whose sensitivity to irradiation-induced cell death changes from the sensitive to resistant stage during development.

Objective Drosophila embryos at the radiation-sensitive stage were irradiated at various doses and the radiation sensitivity was tested regarding the appearance of apoptotic cells in the embryos and the embryonic lethality. Cell fates of the neural stem cells called neuroblasts (NBs) and adult motor function after irradiation were also investigated.

Result Irradiation of Drosophila embryos at the radiation-sensitive stage resulted in a dose-dependent increase in the number of embryos containing apoptotic cells $75 \mathrm{~min}$ after treatment starting at $3 \mathrm{~Gy}$. Embryonic lethality assayed by hatch rate was induced by $1 \mathrm{~Gy}$ irradiation, which did not induce cell death. Notably, no apoptosis was detected in NBs up to $2 \mathrm{~h}$ after irradiation at doses as high as $40 \mathrm{~Gy}$. At $3 \mathrm{~h}$ after irradiation, as low as $3 \mathrm{~Gy}$, the number of NBs marked by Dpn and Klu was decreased by an unidentified mechanism regardless of the cell death status of the embryo. Furthermore, embryonic irradiation at $3 \mathrm{~Gy}$, but not $1 \mathrm{~Gy}$, resulted in locomotor defects in surviving adults.

Conclusion Embryonic NBs survived irradiation at doses as high as $40 \mathrm{~Gy}$, while cells in other parts of the embryos underwent apoptosis at doses higher than $3 \mathrm{~Gy}$ within $2 \mathrm{~h}$ after treatment. Three hours after exposure to a minimum dose of $3 \mathrm{~Gy}$, the number of NBs marked by Dpn and Klu decreased, and the surviving adults exhibited defects in locomotor ability.
\end{abstract}

Keywords Drosophila embryo $\cdot$ Ionizing radiation $\cdot$ Neuroblasts $\cdot$ Cell death $\cdot$ DNA damage response

\begin{tabular}{ll}
\multicolumn{2}{l}{ Abbreviations } \\
IR & Ionizing radiation \\
NB & Neuroblast \\
DDR & DNA damage response \\
AEL & After egg laying \\
PBS & Phosphate-buffered saline
\end{tabular}

Young-Han Song

ysong@ hallym.ac.kr

Ram Wagle

ramwagle7@gmail.com

1 Department of Biomedical Gerontology, Hallym University, Chuncheon, Gangwon-do, Republic of Korea

2 Ilsong Institute of Life Science, Hallym University, Anyang, Gyeonggi-do, Republic of Korea

\section{Introduction}

Exposure to radiation at an early age can occur accidentally or intentionally. For instance, cranial radiation therapy is one of the major treatments for pediatric tumors of the central nervous system. Despite attempted eradication of cancer cells by radiation, there is a growing concern over toxicity due to damage to normal cells, resulting in neurological side effects in the surviving adults. Ionizing radiation (IR) activates the DNA damage response (DDR), including cell cycle arrest, senescence, differentiation, and cell death in normal cells. Cell fate upon irradiation varies depending on the dose of IR exposure and the type and developmental stage of the cells at irradiation (Ruiz De Almodóvar et al. 1994; Zhao et al. 2019). Given the central role of stem cells in maintaining tissue homeostasis, understanding the DDR in neural stem cells is important for managing the neurological effects from irradiation. Furthermore, it will provide 
valuable clues for designing efficient treatment strategies to reduce the toxic effects associated with radiation therapy in pediatric brain tumors.

Drosophila has served as a valuable model organism for studying DDR during neurogenesis. Neurogenesis in Drosophila occurs in two phases during the embryogenesis and larval stages. Radiation exposure during larval neurogenesis affects brain growth, adult lifespan, and locomotor ability (Poodry and Woods 1990; Halme et al. 2010; Sudmeier et al. 2015). At the cellular level, radiation of larvae induces a loss of neural stem cells by premature differentiation rather than cell death (Wagle and Song 2020). Neurogenesis in Drosophila embryos begins with the formation of neural stem cells, called neuroblasts (NBs), after delaminating from the neuroectodermal layer at 4-7 h after egg laying (AEL), corresponding to stages 9-11 of embryonic development. NBs can be identified using a variety of molecular markers, including deadpan (dpn), asense, snail, worniu, hunchback, Kruppel, miranda, inscuteable, and klumpfuss (klu) (Urbach and Technau 2003; Southall and Brand 2009; Harding and White 2018). Each NB divides asymmetrically to self-renew and produces a ganglion mother cell that divides only once, giving rise to post-mitotic neurons or glial cells (Homem and Knoblich 2012). Radiation sensitivity in terms of radiation-induced cell death changes during embryogenesis from radiation-sensitive (until stage 11) to radiation-resistant (after stage 12) (Zhang et al. 2008). Embryonic neurogenesis begins during the radiation-sensitive stage. However, the cellular response of neural stem cells irradiated at the radiation-sensitive stage has not been studied, and its effect on neurogenesis and central nervous system (CNS)-related function is not known.

To understand how NBs in the radiation-sensitive stage embryos respond to IR, we investigated the radiation sensitivity of embryos and the response of embryonic NBs following exposure to different doses of IR. We found a dosedependent increase in embryonic lethality, as assayed by hatch rate after exposure to varying doses of IR. Within $2 \mathrm{~h}$ of irradiation, NBs were resistant to IR-induced cell death, even at $40 \mathrm{~Gy}$. In contrast, $3 \mathrm{~Gy}$ was sufficient to increase the number of embryos containing apoptotic cells. Eventually, the number of NBs marked by Dpn and Klu decreased $3 \mathrm{~h}$ after exposure at as low as $3 \mathrm{~Gy}$, independent of the cell death status of the embryo, and surviving adults exhibited impaired locomotor abilities.

\section{Results}

\section{Radiation sensitivity of Drosophila embryos irradiated at the radiation-sensitive stage}

Sensitivity to irradiation-induced cell death changes during embryonic development (Zhang et al. 2008). Embryos at developmental stages 1-11 are highly sensitive to irradiation-induced cell death; however, these embryos become resistant when irradiated at later developmental stages (Zhang et al. 2008). The lethality of the irradiated embryos, assayed as the hatch rate, is similarly changed during development (Zhang et al. 2008). To investigate the radiation sensitivity of early-stage embryos in more detail, embryos at 4-7 h AEL (stages 9-11, referred to as the radiation-sensitive stage) were irradiated with various doses of IR and tested for their sensitivity to cell death and lethality. IR-induced cell death was determined by staining irradiated embryos with active cleaved Dcp1 (cDcp1, Drosophila caspase) to mark apoptotic cells 75 min post-irradiation. Low levels of cell death detected in the absence of irradiation did not increase after $1 \mathrm{~Gy}$ irradiation. Irradiation with 3 Gy significantly increased the number of cDcp1-positive cells on the surface of the embryos in $52 \%$ of the irradiated embryos (Fig. 1B, C). As the dose of irradiation increased, the number of cDcp1-positive cells in the embryo and the percentage of cDcp1-stained embryos increased up to $100 \%$ at $40 \mathrm{~Gy}$ (Fig. 1B, C). Embryonic lethality, assayed as hatch rate, also increased in a dose-dependent manner, even at $1 \mathrm{~Gy}$, which did not induce cell death in the embryos (Fig. 1D). These results suggest that IR induced cell death in radiation-sensitive stage embryos at a threshold dose of $3 \mathrm{~Gy}$, while IR-induced lethality increased in a dose-dependent manner.

\section{Radiation sensitivity of NBs irradiated at the radiation-sensitive stage}

When second-instar larvae are irradiated at $40 \mathrm{~Gy}$, NBs in the larval brain undergo premature differentiation rather than apoptotic cell death (Wagle and Song 2020). To test whether the NBs in the embryos were also resistant to irradiation-induced cell death, the radiation-sensitive stage embryos were irradiated at $40 \mathrm{~Gy}$ and the embryos were stained with cDcp 1 and Dpn to detect apoptotic cells and NB, respectively, at 75 min after treatment (Fig. 2). Unlike the surface of the embryos (indicated as ' $a$ ' in Fig. 1A), where the number of cDcp1-positive cells greatly increased after irradiation (Fig. 2, left panel), in the NB layer (indicated as 'b' in Fig. 1A), no cDcp1 signal was 
A
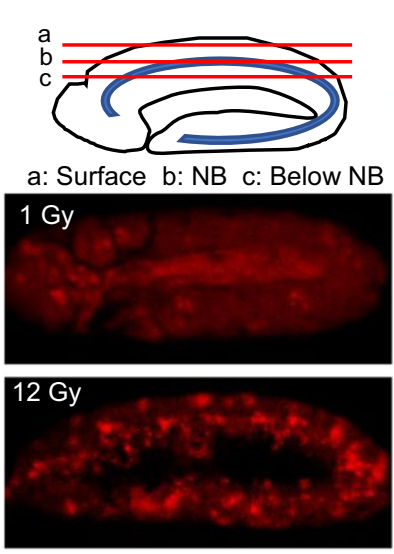

B
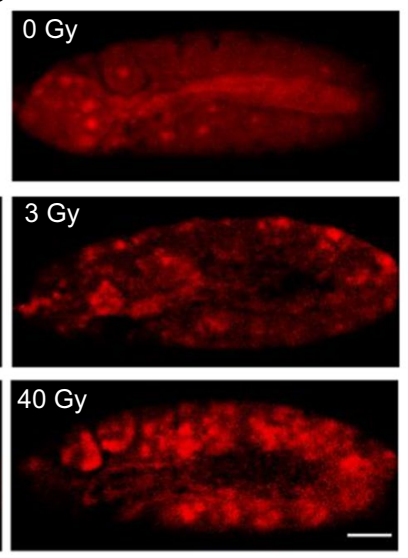

cDcp 1 (apoptotic cells)

C

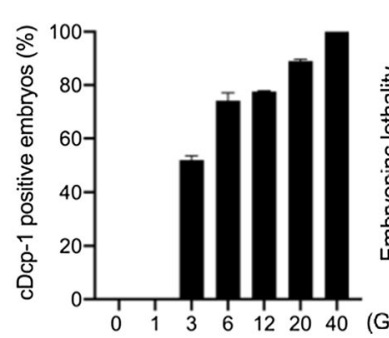

D

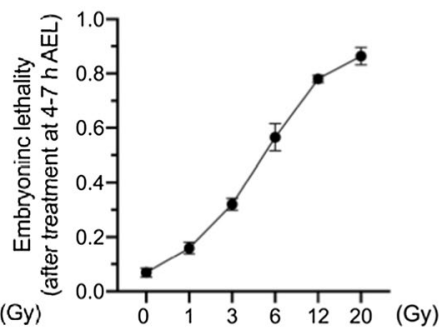

Fig. 1 Radiation sensitivity of embryos at stages 9-11. A Schematics of a lateral view of a Drosophila embryo. The confocal sections analyzed in this study are indicated as the surface (a), neuroblast (NB) (b), and below NB (c) layers, which contain irradiation-induced apoptotic cells, NBs, and differentiated progenies, respectively. The blue line represents the ventral nerve chord. The head is oriented towards the left in (A) and in all subsequent figures. B Wild-type embryos were irradiated with the indicated doses of ionizing radiation (IR) and stained with cDcp1 (red) after 75 min. Representative images of lateral views of embryos are shown. Scale bars, $50 \mu \mathrm{m}$. C Bar graph showing the percentage of embryos with a higher cDcp1 signal at indicated doses of IR compared to the basal level at $0 \mathrm{~Gy}$. Values represent mean \pm standard deviation from two independent experiments. At least 250 embryos were analyzed for each treatment. D Wild-type embryos were irradiated at indicated doses of IR. Embryonic lethality was determined as the percentage of embryos that failed to hatch after $30 \mathrm{~h}$. At least 521 embryos were observed for each treatment from two independent experiments

detected in the Dpn-positive NBs (Fig. 2, right two panels). These results show that even in the radiation-sensitive stages, embryonic NBs are resistant to irradiation-induced cell death.

\section{Mechanisms for the survival of NBs irradiated at the radiation-sensitive stage}

Irradiation-induced cell death of Drosophila somatic cells requires transcriptional induction of proapoptotic genes including hid, reaper, and grim, by activating the transcription factor $p 53$. The lack of irradiation-induced cell death in late-stage embryos is due to epigenetic blocking of hid/reaper induction (Zhang et al. 2008). To test if a lack of NB deaths in radiation-sensitive stage embryos occurs through this mechanism, hid and reaper transcripts were determined by fluorescence in situ hybridization (FISH). In the wild-type embryos, hid transcript detected with antisense RNA probe was rapidly induced within $1 \mathrm{~h}$ after IR in a characteristic pattern closely resembling cell death (Fig S1A). The negative control performed with sense probe did not produce signal after irradiation (Fig S1B). Consistent with previous reports (Zhang et al. 2008), reaper transcript was similarly induced after irradiation (data not shown). In contrast, hid (Fig. 3A) and reaper (data not shown) were not induced in NBs marked by Dpn, suggesting that a lack of hid and reaper induction is responsible for the survival of irradiated NBs.

To test whether forced expression of hid/reaper can induce cell death of NBs, the Gal4-UAS system was used to overexpress these genes in the NBs. The Gal4 transcription factor driven by an NB-specific promoter from Inscuteable gene (Insc-Gal4) recognizes the UAS sequence and activates the transcription of the downstream genes, hid and reaper (UAS-hid/reaper). Overexpression of hid/reaper in NBs resulted in cell death of NBs marked by Insc $>$ mCD8GFP and Dpn staining in the stage 11 embryos (Fig. 3B, second row). Conversely, overexpression of the upstream transcription factor $p 53$ did not induce NB death (Fig. 3B, third row). These results suggest that $p 53$-mediated transcriptional induction of hid/reaper is attenuated in irradiated NBs.

To investigate whether the survival of irradiated NBs is due to epigenetic blocking of hid/reaper induction, mutants for histone modifiers, including $\mathrm{Su}(\mathrm{Z}) 12$ [3], $\mathrm{Su}$ (var)3-9[2], $H D A C 1$ [04556], and $P C[1]$ were irradiated and tested for cDcp1 staining in the NBs. Although reaper transcripts were induced in these mutant embryos when irradiated at the radiation-resistant stage (Fig S2A), cell death was not detected in the NBs irradiated at the radiation-sensitive stage (Fig S2B). These results suggest that the survival of irradiated NBs in radiation-sensitive stage embryos is due to a lack of proapoptotic gene induction but may not result from epigenetic blocking of these genes. Further research will be necessary to elucidate the underlying mechanism for the lack of proapoptotic gene induction in irradiated NBs.

\section{Fate of NBs irradiated at the radiation-sensitive stage}

In addition to programmed cell death, irradiated stem cells can undergo cell cycle arrest, premature differentiation, or senescence. To investigate the fate of the irradiated NBs, cell proliferation of the NBs was tested by staining with phospho-histone H3 (PH3) to mark mitotic cells. When the 

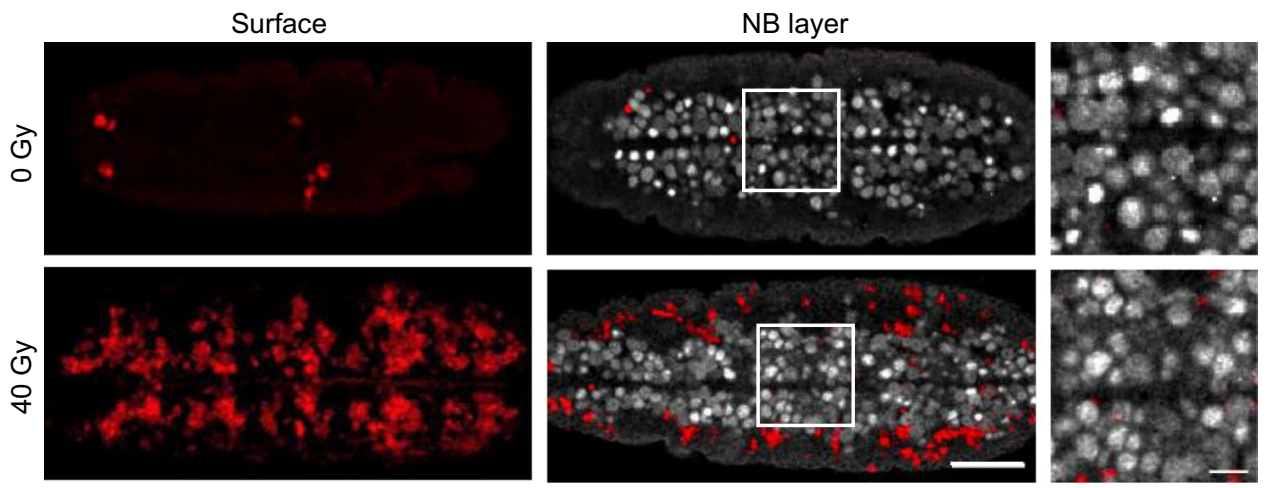

cDcp 1 (apoptotic cells) Dpn (neuroblasts)

Fig. 2 Radiation response of neuroblasts (NBs) in radiation-sensitive stage embryos. Wild-type embryos were irradiated at $40 \mathrm{~Gy}$. At 75 min after treatment, embryos were stained with cDcp1 (red) and Dpn (gray) to detect apoptotic cells and NBs, respectively. Representative images of the ventral view taken from the same embryo for

number of NBs marked by both Insc $>$ GFP and Dpn were counted at 1 and $2 \mathrm{~h}$ after irradiation, no significant difference was observed after irradiation (Fig. 4A, B). The percentage of PH3-positive NBs significantly increased after irradiation $(42.6 \pm 13.0 \%$ and $37.1 \pm 7.4 \%$ at 1 and $2 \mathrm{~h}$ after IR, respectively) compared to that in the absence of irradiation $(20.9 \pm 6.4 \%$ and $20.5 \pm 5.0 \%$ at 1 and $2 \mathrm{~h}$ without IR, respectively) (Fig. 4A, C).

To test whether the increase in PH3-positive NBs 1 and $2 \mathrm{~h}$ after irradiation resulted in a corresponding increase in $\mathrm{NBs}$, the number of NBs was determined at $3 \mathrm{~h}$ after irradiation using various markers. When Insc $>$ mCD8GFP was used as a marker for NB, a GFP signal was not detected $3 \mathrm{~h}$ after irradiation (Fig. 5A), which is in contrast to the observation at 1 and $2 \mathrm{~h}$ after irradiation (Fig. 4A). When other NB markers including Dpn and Klu, were used, a similar number of NBs were stained with either Dpn $(89.5 \pm 8.9)$ or Klu (86.1 \pm 7.7$)$, or with both Dpn and Klu (86.1 \pm 7.7$)$ in the absence of irradiation. At $3 \mathrm{~h}$ after irradiation, the NB number reduced more than twofold $(41.6 \pm 6.5$, Dpn positive; 42.2 \pm 8.4 , Klu positive; $30.2 \pm 5.1$, both Dpn and Klu positive) (Fig. 5B, C). As a higher number of NBs were positive with only Dpn or Klu after irradiation, compared to that with both markers, the expression patterns of these markers were investigated in more detail. Compared to that in non-irradiated embryos, the number of NBs expressing Dpn but not Klu (0 Gy vs 40 Gy, $3.4 \pm 3.5$ vs $11.5 \pm 5.1)$ and that expressing Klu but not Dpn ( 0 Gy vs 40 Gy, $0.0 \pm 0.0$ vs $12.0 \pm 7.4$ ) was significantly higher in irradiated embryos at $3 \mathrm{~h}$ post-irradiation (Fig. 5B [right two panels], D). Taken together, our results show that the number of NBs marked by Dpn and Klu was severely reduced $3 \mathrm{~h}$ after irradiation, each treatment showing cDcp1 signals in the surface (left panel) and NB layers (right two panels) are presented. A magnified image of the region marked with a white rectangle is shown on the right. Scale bars: whole embryo, $50 \mu \mathrm{m}$; magnified view, $20 \mu \mathrm{m}$

and the stem cell markers, including Insc promoter activity and expression of Dpn or Klu, were dysregulated after IR.

As most embryos irradiated at 20 Gy or higher did not develop properly and failed to hatch (Fig. 1C), the loss of irradiated NBs may be the result of the systemic failure of the entire embryo that undergoes cell death. To test whether the loss of irradiated NBs has physiological relevance, the number of NBs marked by Dpn was determined after lower dose irradiation (Fig. 6). Irradiation at $1 \mathrm{~Gy}$, which did not induce cell death in the embryo, did not reduce the number of NBs. In contrast, the number of NBs after irradiation with 3 and 12 Gy decreased regardless of whether cell death in the embryo was induced (Fig. 6). This result suggests that the loss of NB after irradiation is not likely to be due to embryonic lethality.

To investigate the mechanism underlying the loss of irradiated NB, the embryos were stained with apoptosis markers, including acridine orange, ethidium bromide, cDcp1, or TUNEL (Fig. 7). At $3 \mathrm{~h}$ after irradiation, the NBs were not stained with these markers, suggesting that the loss of irradiated NBs was not due to apoptotic cell death. Mutation of p53 was unable to rescue the loss of irradiated NBs (data not shown), further supporting that the loss of irradiated NBs was not due to apoptotic cell death. Irradiated NBs in the Drosophila larval brain undergo premature differentiation, marked by the nuclear localization of the differentiationpromoting transcription factor Prospero (Pros) in the NBs (Wagle and Song 2020). Pros is not active in NBs due to its segregation in the cytoplasm, and nuclear Pros triggers differentiation. Notably, the number of Pros-positive cells and the intensity of the Pros signal were severely reduced after irradiation (Fig. 8). Due to the lack of a sufficient number of Pros-positive cells, it was difficult to conclude whether 
Fig. 3 Role of hid, reaper, and p53 genes in the survival of irradiated neuroblasts (NBs) at the radiation-sensitive stage. A Wild-type embryos were irradiated at $40 \mathrm{~Gy}$. One hour later, embryos were subjected to fluorescence in situ hybridization to detect hid (green, a-d) transcripts. The NBs were co-stained with Dpn (red, a-d) and are indicated with dotted circles. Representative images of the ventral view showing the surface ( $a$ and $b$ ) and NB layers ( $c$ and d) taken from the same embryo are shown. Scale bars, $20 \mu \mathrm{m}$. B Insc-Gal4 driver was used to overexpress hid, reaper, and p53. Embryos at late stage 11 were stained with cDcp1 (red), and Dpn (gray) and GFP (green) to detect apoptotic cells and NBs, respectively. Representative images of the ventral view showing embryos expressing mCD8GFP alone (Insc $>m C D 8 G F P$; first row), hid and reaper (Insc $>m C D 8 G F P$, hid, reaper; second row), or $\mathrm{p} 53$ (Insc $>m C D 8 G F P$, p53; third row) are shown. Magnified images of the region indicated with white rectangles are shown on the right. Scale bars: whole embryo, $50 \mu \mathrm{m}$; magnified images, $20 \mu \mathrm{m}$
A

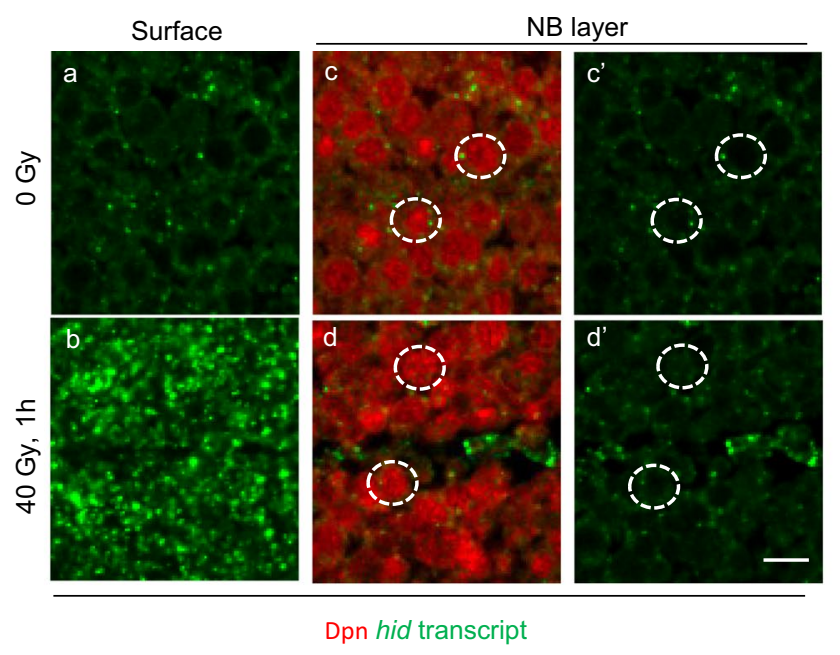

B
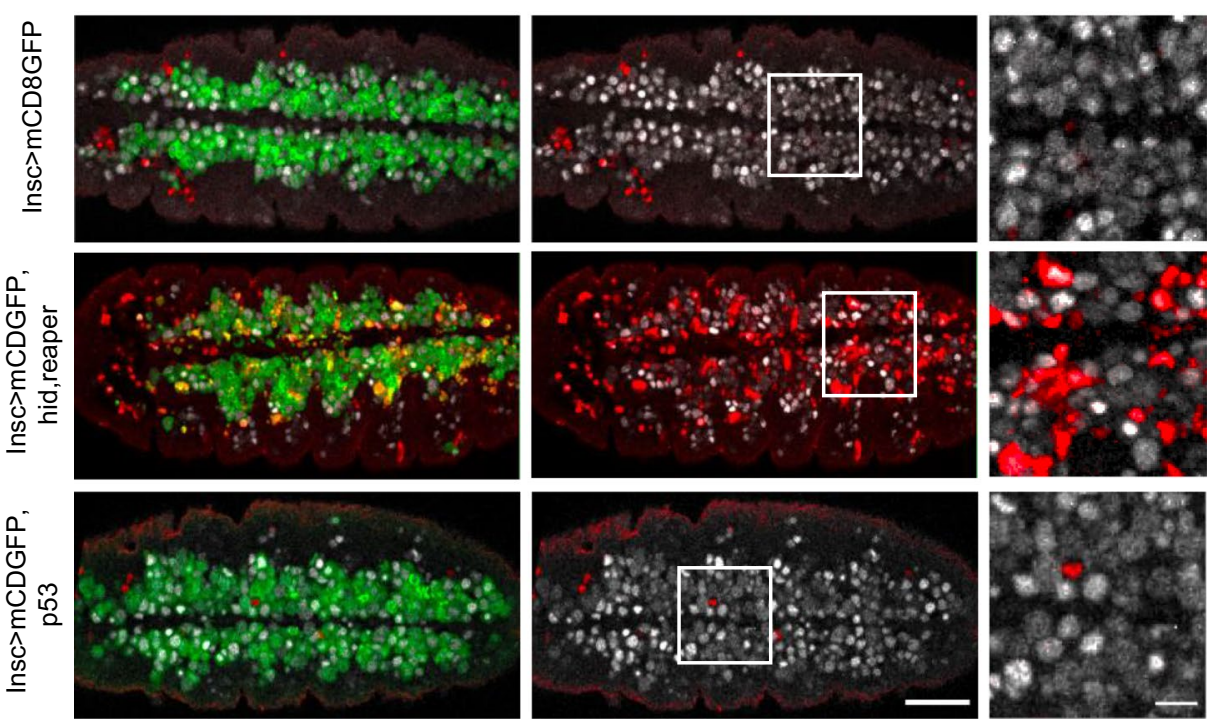

Insc>mCDGFP

Dpn cDcp 1

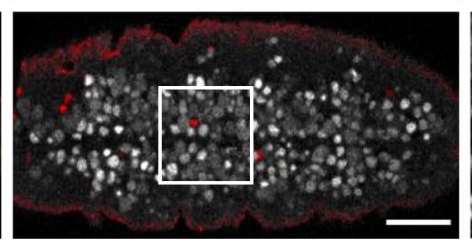

Dpn cDcp 1

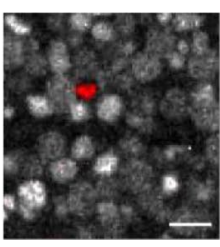

Dpn cDcp 1 premature differentiation occurred in the irradiated NBs. Additionally, the number of neurons stained by the panneuronal marker Elav was reduced (Fig. 8, third row), suggesting that irradiation may affect embryonic neurogenesis.

\section{Effect of irradiation in radiation-sensitive stage embryos on the locomotor ability of surviving adults}

The neurological function of surviving adults was investigated to evaluate the long-term effects of embryonic irradiation during development. Climbing assays based on negative geotactic tendency are well-established methods for evaluating neurological activity involving sensory input, central processing, and motor output. Wild-type adult flies dropped to the bottom of the culture vial after gentle tapping will rapidly climb towards the top. In the absence of irradiation, $88.0 \pm 3.4 \%$ of wild-type flies passed the test (Fig. 9). Irradiation of the embryos at $1 \mathrm{~Gy}$, which did not induce cell death in the embryo, did not affect the climbing ability. Conversely, 3 Gy $(39.9 \pm 2.4 \%)$ and 6 Gy $(34.6 \pm 1.4 \%)$ irradiation, which lead to embryonic cell death and NB loss, resulted in a severe reduction in the climbing pass rate (Fig. 9). These results show that a threshold dose of irradiation of $3 \mathrm{~Gy}$ in this case induced apoptotic cell death, NB loss, and defective locomotive ability. 
A

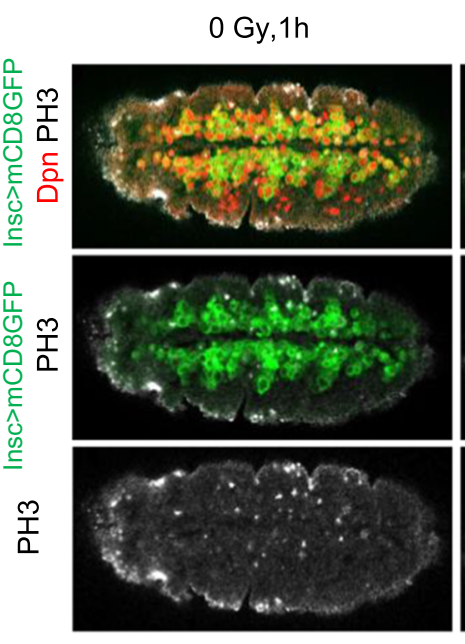

$40 \mathrm{~Gy}, 1 \mathrm{~h}$
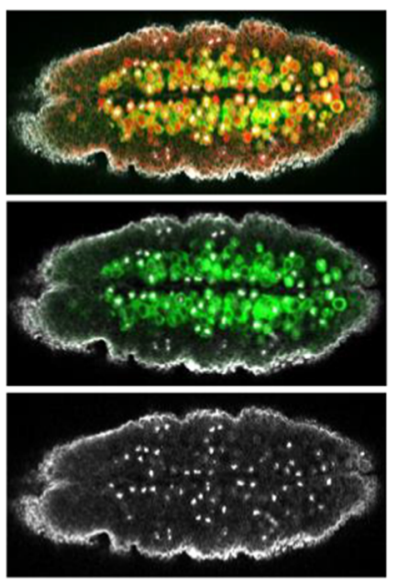

$0 \mathrm{~Gy}, 2 \mathrm{~h}$
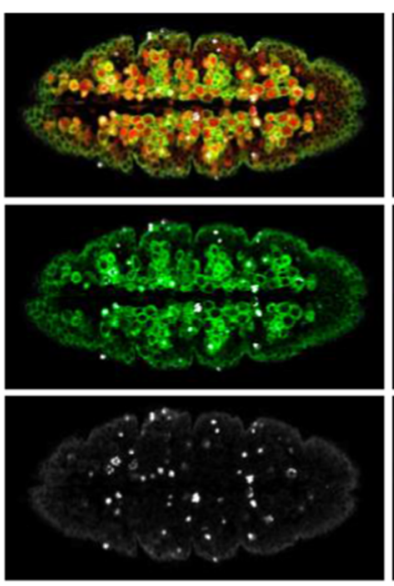

$40 \mathrm{~Gy}, 2 \mathrm{~h}$

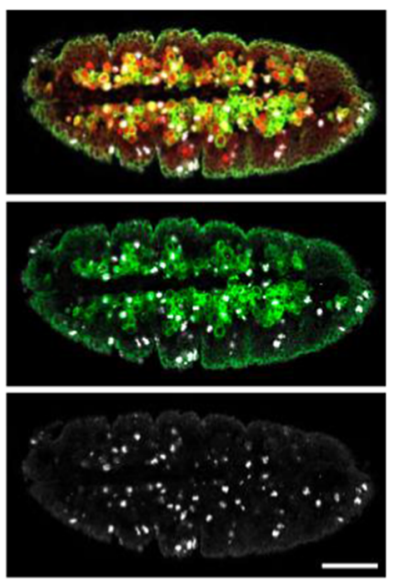

B

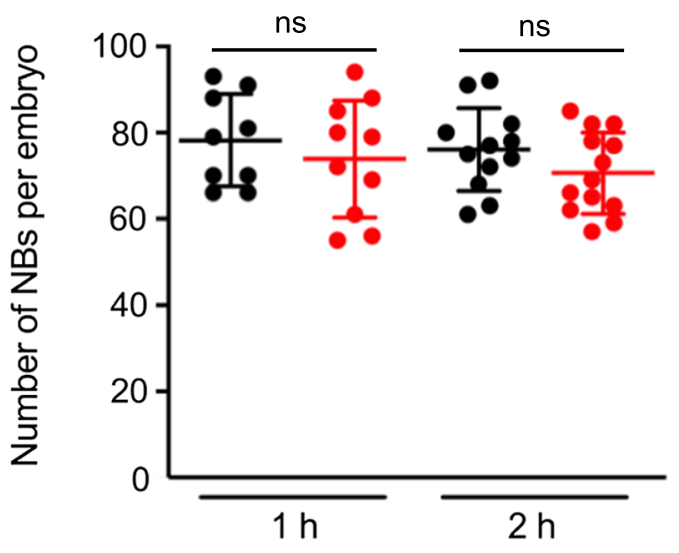

Fig. 4 Effect of ionizing radiation on the proliferation of neuroblasts (NBs). A Insc $>m C D 8 G F P /+$ embryos were irradiated at $40 \mathrm{~Gy}$ and stained with PH3 (gray), Dpn (red), and GFP (green) after 1 and $2 \mathrm{~h}$ to label the proliferating cells and NBs, respectively. Scale bars, $50 \mu \mathrm{m}$. B, C Dot plot showing the number (B) and percentage

\section{Discussion}

Here, we treated radiation-sensitive stage embryos with different doses of IR and studied their effects on embryonic NBs and locomotor activity in surviving adults. Irradiation at doses of $3 \mathrm{~Gy}$ or higher increased the percentage of embryos with apoptotic cells. Moreover, irradiated NBs, which seemed to survive within $2 \mathrm{~h}$ after irradiation, were lost at $3 \mathrm{~h}$ after irradiation starting from $3 \mathrm{~Gy}$, regardless of the cell death status of the embryo. Consequently, poor locomotor activity was observed in the surviving adults after irradiating embryos at doses of $3 \mathrm{~Gy}$ or higher, but not at $1 \mathrm{~Gy}$, which did not induce cell death in the embryos.

IR is known to affect neurological development and, consequently, functions related to the nervous system in several
C

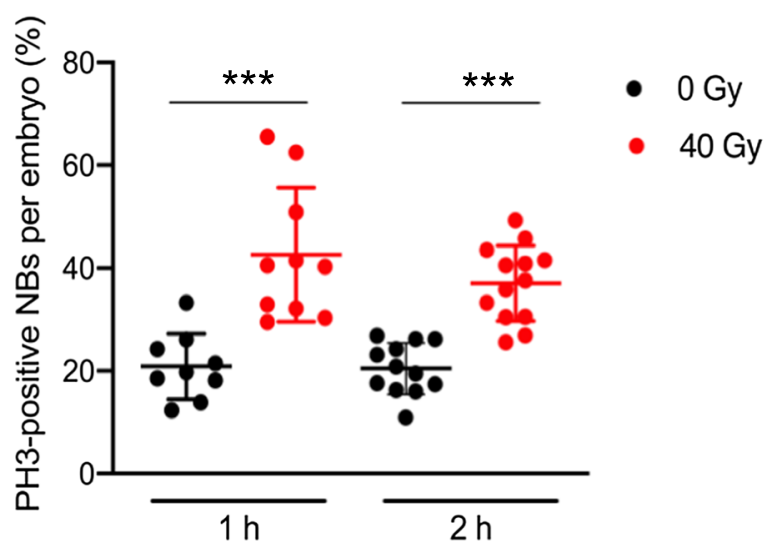

of PH3-positive NBs (C) after 1 and $2 \mathrm{~h}$ at 0 and 40 Gy. Each dot represents a number and percentage of $\mathrm{PH} 3$-positive NBs in a single embryo. At least $55 \mathrm{NBs}$ from each embryo were analyzed. Bars represent the mean \pm standard deviation from two independent experiments. $* * * p \leq 0.001$

experimental models, including medaka and zebrafish (Yasuda et al. 2006; Zhao et al. 2020). The effects of IR can be detrimental, especially when exposed early in development. Exposure of early-stage Drosophila larvae to IR results in reduced viability, developmental delay, and locomotor defects associated with poor CNS function (Sudmeier et al. 2015). The phenotypic severity depends on the dose and age of the larvae at irradiation, exhibiting a more severe phenotype when irradiated at an earlier stage with a higher dose. Although IR exposure of larvae induces apoptosis in the neurons of the adult brain (Sudmeier et al. 2015), premature differentiation rather than apoptosis is induced in larval NBs following exposure of second-instar larvae to 40 Gy IR (Wagle and Song 2020). Here, we showed that irradiating Drosophila embryos at the radiation-sensitive 
A
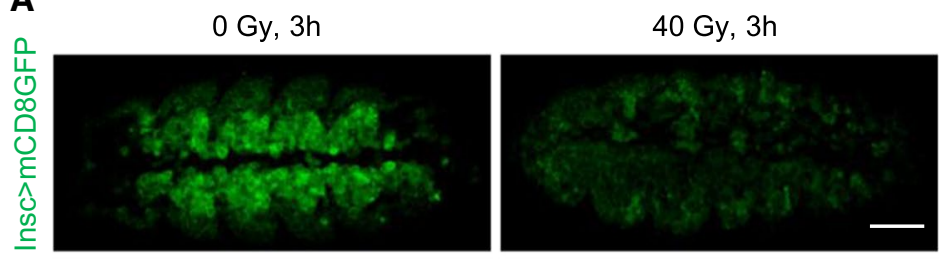

B

$0 \mathrm{~Gy}, 3 \mathrm{~h}$
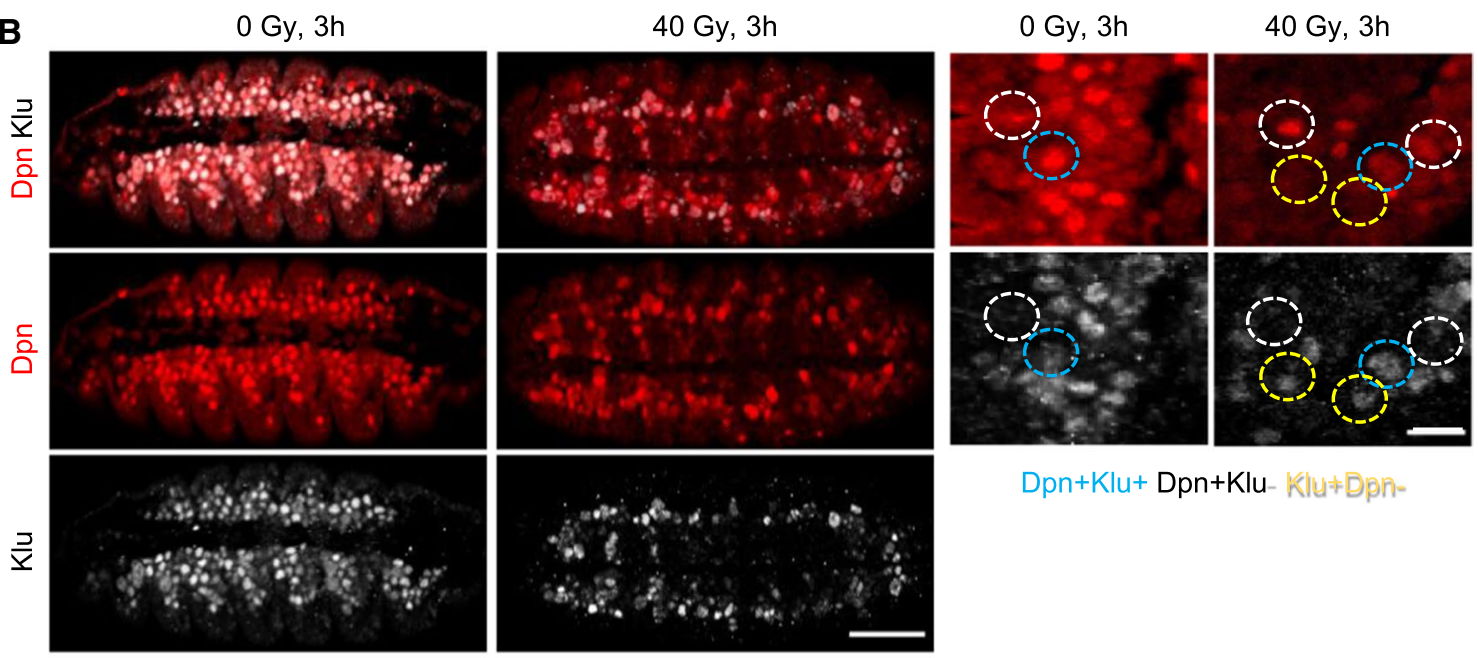

$\mathrm{Dpn}+\mathrm{Klu}+\mathrm{Dpn}+\mathrm{Klu}-\mathrm{Klu}+\mathrm{D} p h-$

C

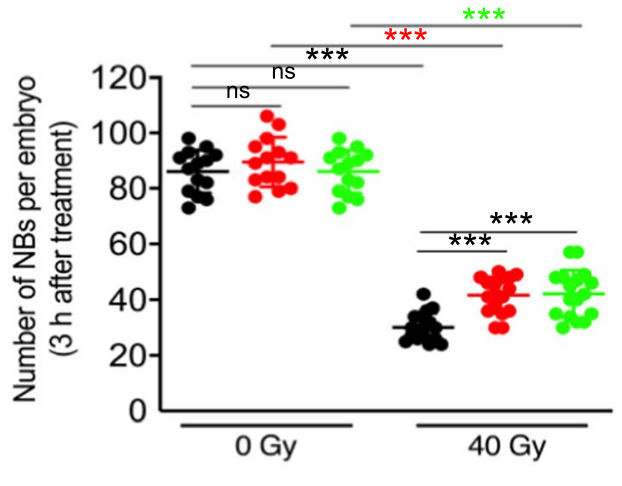

- Dpn+Klu+ • Dpn+ • Klu+
D

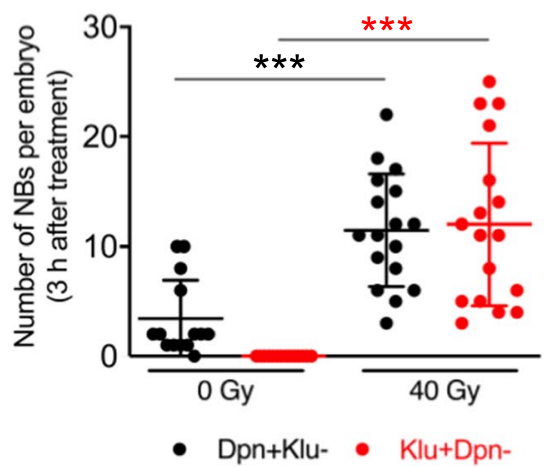

dot represents the number of NBs in an embryo. NBs were counted as cells stained with either Dpn (Dpn+) or Klu (Klu+) as well as those stained with both markers $(\mathrm{Dpn}+\mathrm{Klu}+)$. Bars represent the mean \pm standard deviation (SD) from two independent experiments. At least 14 embryos were analyzed for each treatment. ns, not significant, $* * * p \leq 0.001$. D Dot plot showing the number of NBs differentially stained with Dpn or Klu per embryo at $3 \mathrm{~h}$ after 40 Gy irradiation. Each dot represents the number of NBs in a single embryo. NBs were counted as cells stained with Dpn but not Klu (Dpn+ Klu-) or Klu but not Dpn (Klu+ Dpn-). Bars represent the mean \pm SD from two independent experiments. At least 14 embryos were analyzed for each treatment. $* * * p \leq 0.001$

of all the neurons that will be incorporated into the larval CNS and $10 \%$ of the total cells in the adult CNS (Prokop and Technau 1991; Homem and Knoblich 2012). The poor locomotor activity of surviving adults developed from the stage with a dose of $3 \mathrm{~Gy}$ or higher reduced the number of embryonic NBs marked by Dpn and Klu (Fig. 5) and affected the locomotor function of surviving adults (Fig. 9). Embryonic NB divisions are responsible for the production 
A
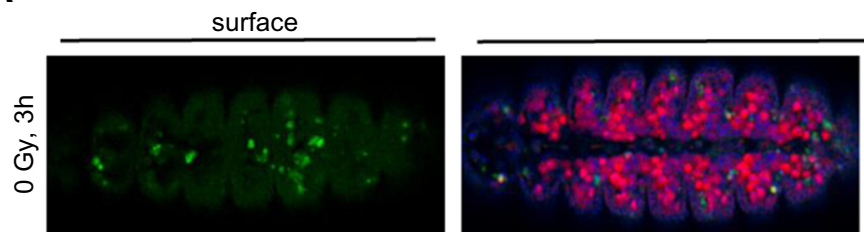

NB layer
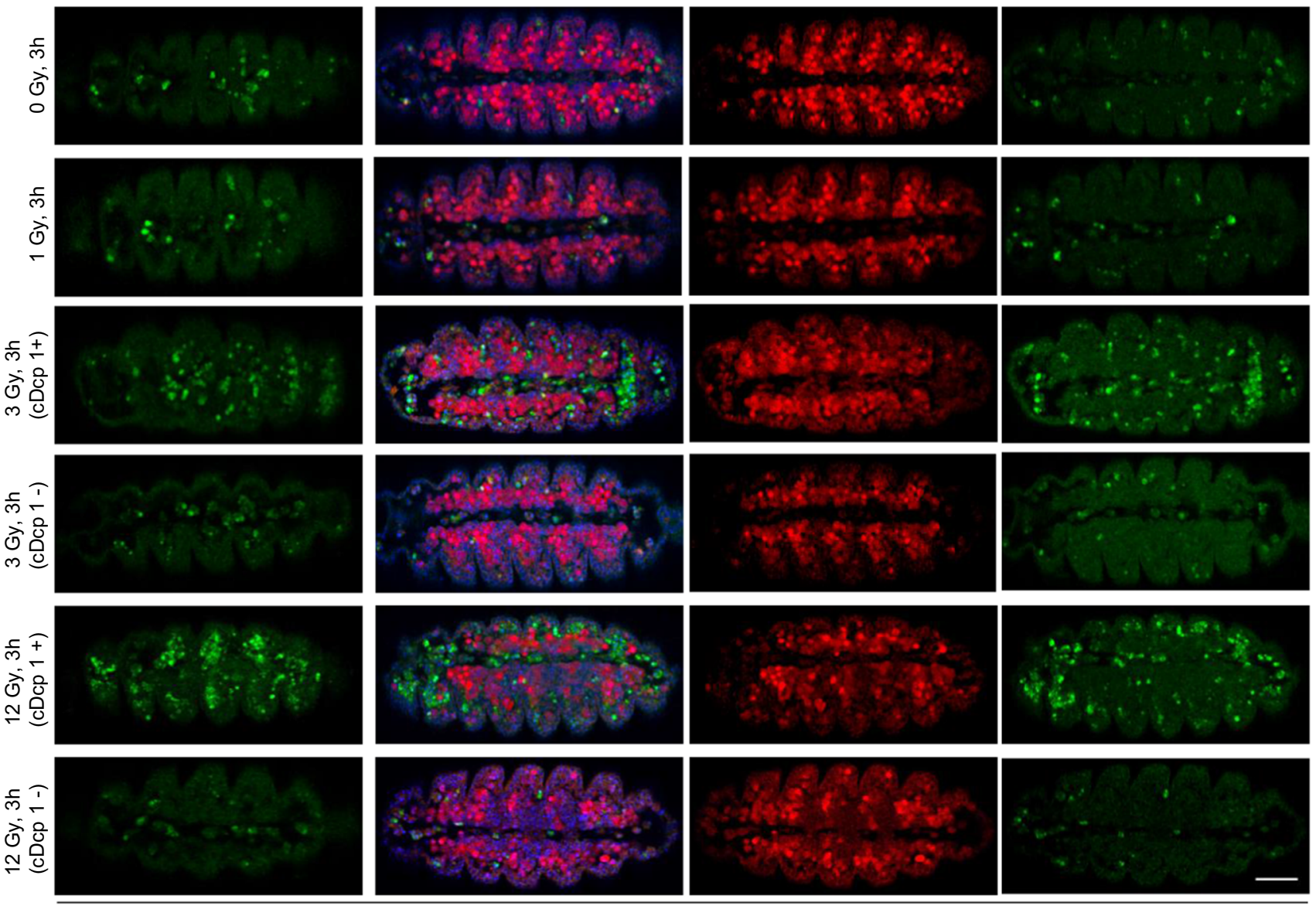

cDcp-1 Dpn DAPI

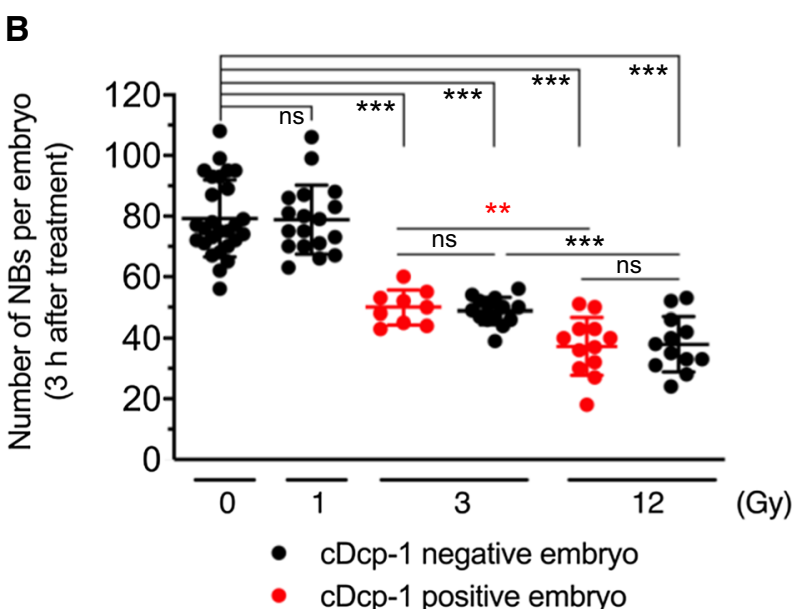

Fig. 6 Effect of different doses of ionizing radiation on the number of neuroblasts (NBs). A Wild-type embryos were irradiated at 1, 3, and 12 Gy. After $3 \mathrm{~h}$, embryos were stained with cDcp1 (green), Dpn (red), and 4',6-diamidino-2-phenylindole (DAPI; blue) to detect apoptotic cells, NBs, and DNA, respectively. Representative images of the surface (left panel) and NB layers (right three panels) taken from the same embryo from at least two independent experiments are shown.
Scale bars, $50 \mu \mathrm{m}$. B Number of NBs in cDcp1-positive and -negative embryos at $3 \mathrm{~h}$ after treatment with 3 and $12 \mathrm{~Gy}$ irradiation as determined by Dpn staining. Each dot represents the number of NBs in a single embryo. Bars represent the mean \pm standard deviation from two independent experiments. At least 9 embryos were analyzed for each treatment. ns, not significant, $* * * p \leq 0.001, * * p \leq 0.01$ 
A

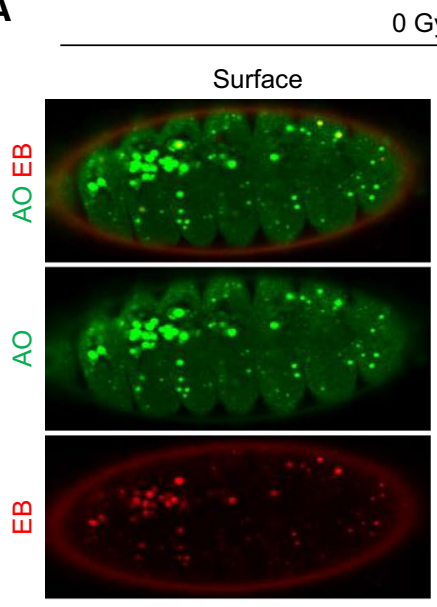

B

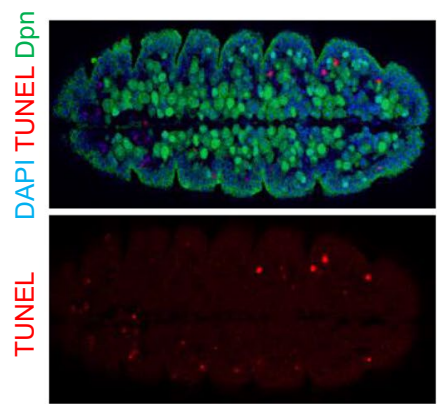

Gy, 3h
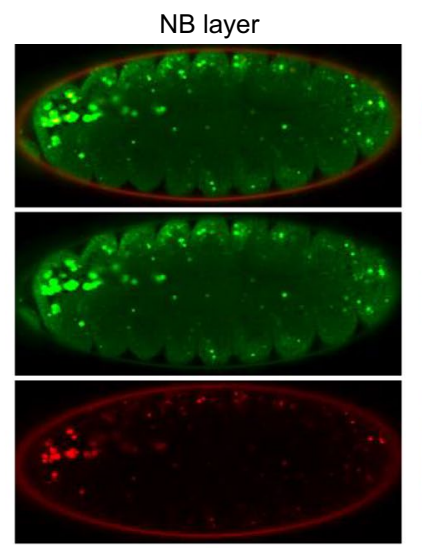

40 Gy, 3h

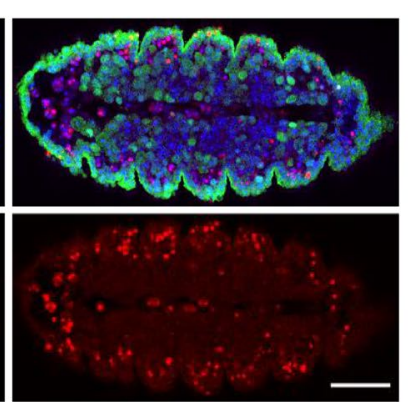

C
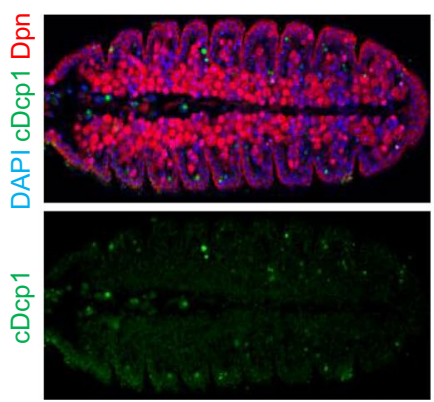

40 Gy, 3h

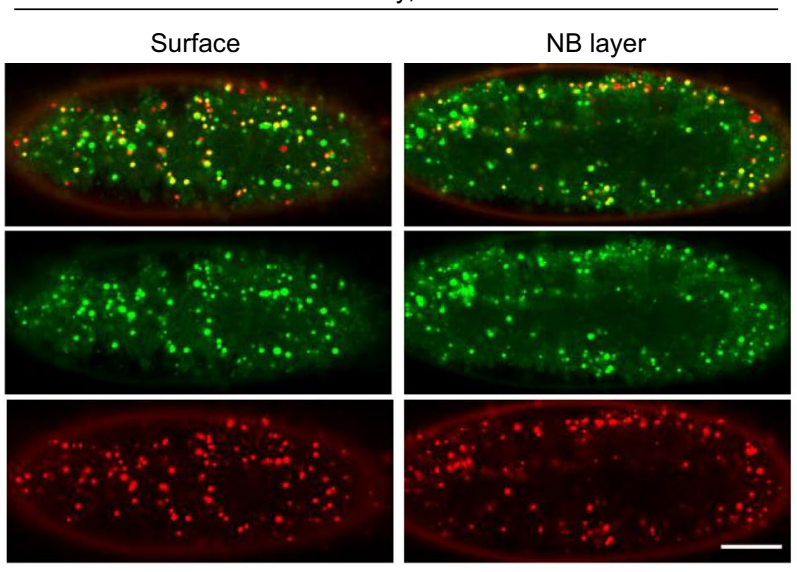

40 Gy, 3h
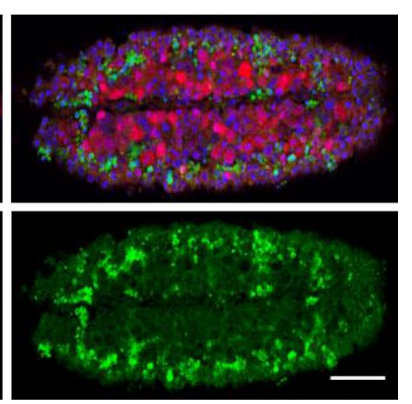

Fig. 7 Role of apoptotic cell death in the loss of irradiated neuroblasts (NBs). A Wild-type embryos were irradiated at $40 \mathrm{~Gy}$. At $3 \mathrm{~h}$ after treatment, embryos were stained with Acridine orange (AO; green) and ethidium bromide (EB; red) to detect apoptotic cells. Representative images of the surface and NB layers taken from the same embryo from at least two independent experiments are shown. Scale bars, $50 \mu \mathrm{m}$. B, C Wild-type embryos were irradiated as

irradiated embryos may be attributed to the reduction in NB numbers marked by Dpn and Klu after IR. However, locomotor defects due to the systemic effect of IR on tissues other than the CNS, such as muscles, cannot be excluded. Given that children undergoing cranial radiation therapy for CNS malignancies are at high risk of radiation-induced toxicity, Drosophila embryos can serve as a model for developing therapeutic interventions aimed at reducing the side effects of IR treatment.

We showed that Drosophila embryonic NBs irradiated at the radiation-sensitive stage were resistant to IR-induced cell death within the first $2 \mathrm{~h}$ after irradiation, while cells on the surface layer of the embryos died (Fig. 2). In line with our results, larval brain NBs (Wagle and Song 2020) and stem cells in the Drosophila adult germline and intestine (Xing et al. 2015) are also resistant to IR-induced cell death. Tyrosine kinase receptor Tie-mediated survival signaling is required for the radiation resistance of adult female germline in $\mathbf{A}$, and after $3 \mathrm{~h}$, embryos were stained with TUNEL (red), Dpn (green), and 4',6-diamidino-2-phenylindole (DAPI; blue) (left panel) or cDcp1(green), Dpn (red), and DAPI (blue) (right panel) to detect apoptotic cells (TUNEL in B or cDCp1 in C), NBs, and DNA, respectively. Representative images from at least two independent experiments are shown. Scale bars, $50 \mu \mathrm{m}$

stem cells (Xing et al. 2015). This mechanism does not seem to function in irradiated embryonic NBs, as irradiated embryonic NBs were resistant to cell death in Tie mutant embryos (data not shown). Developmental stage-specific epigenetic histone modifications of hid and reaper have been reported to be responsible for resistance to IR-induced cell death in Drosophila embryos (Zhang et al. 2008). Although the irradiated NBs lacked induction of hid and reaper genes (Fig. 3A), epigenetic histone modification was not responsible for the lack of cell death (Fig S2). The exact mechanism of radiation resistance in embryonic NBs remains to be determined. Another possible survival mechanism may be the involvement of autophagy, although it can be a pro-survival or cell death-promoting mechanism depending on the context (Noguchi et al. 2020). As autophagy has been shown to play a protective role against stress-induced apoptosis of mesenchymal stem cells after hypoxia/serum deprivation 

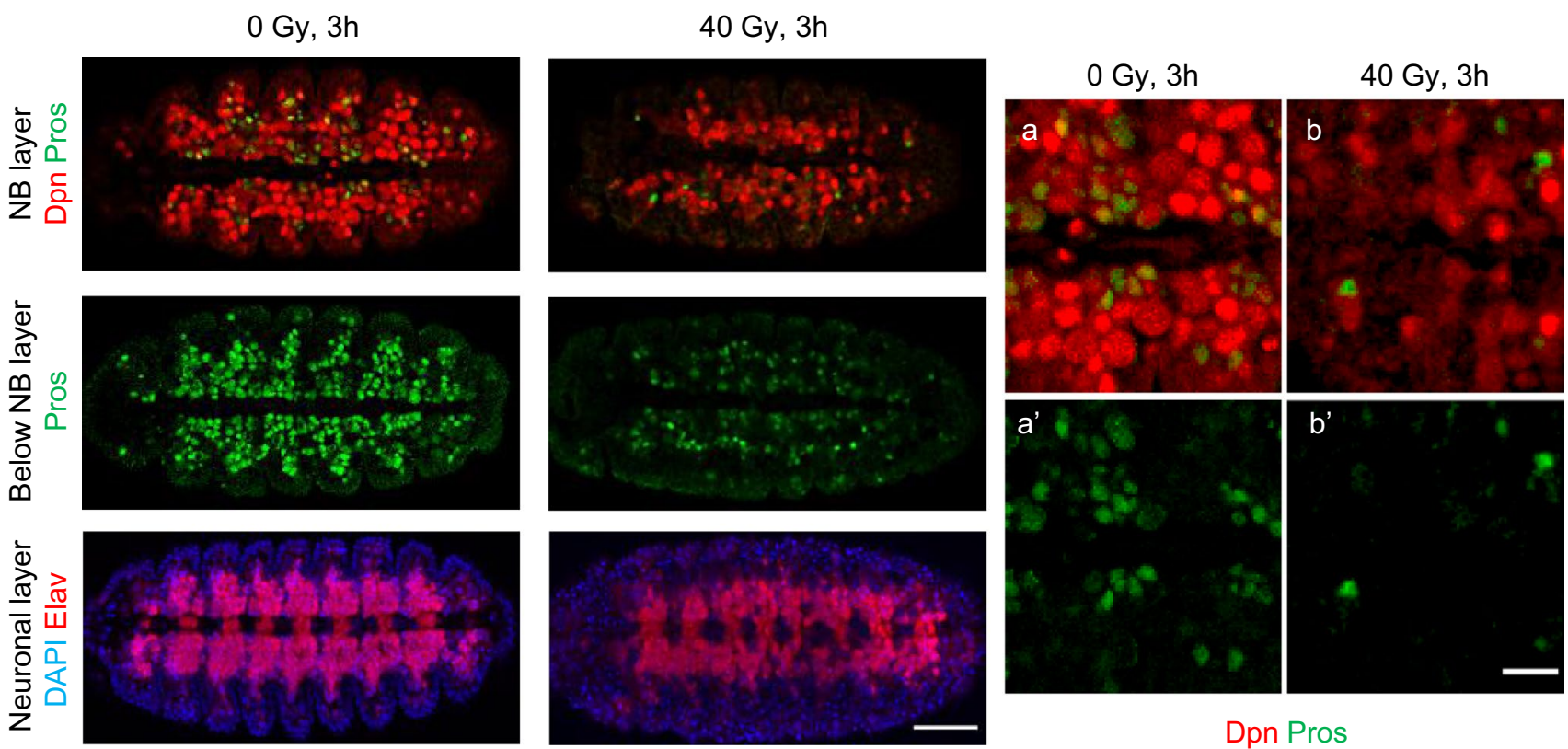

Dpn Pros

Fig. 8 Effect of ionizing radiation on premature differentiation of neuroblasts (NBs). Wild-type embryos were irradiated at $40 \mathrm{~Gy}$. At $3 \mathrm{~h}$ after treatment, embryos were stained with Dpn (red) and Pros (green) (upper left two panels) to detect the NB and differentiated progenies, or Elav (red) and 4',6-diamidino-2-phenylindole (DAPI; blue) (lower left two panels) to detect the neurons and DNA, respec-

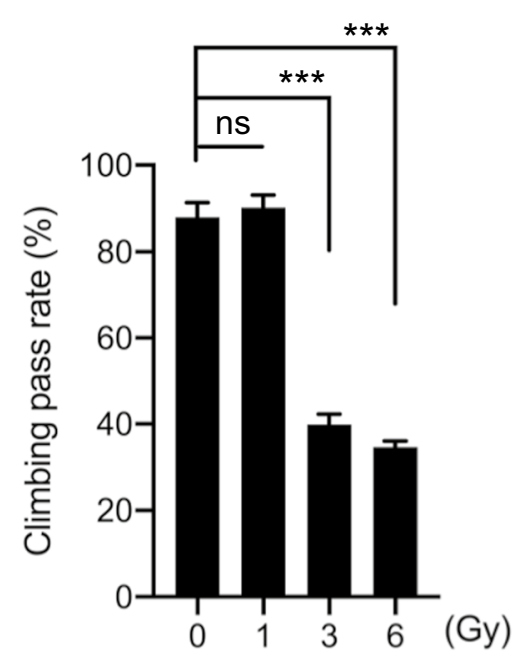

Fig. 9 Effect of low-dose irradiation in radiation-sensitive stage embryos on the locomotive activity of adults. Adults derived from irradiated wild-type embryos were collected and a climbing assay was performed. Bar graph shows the climbing pass rate calculated as the percentage of flies that successfully climbed past a $5 \mathrm{~cm}$ mark within $10 \mathrm{~s}$ after gently tapping them to the bottom. Values represent the mean \pm standard deviation from three independent experiments. For each experiment, the responses from at least two sets of flies (10 flies each) were observed. ns, not significant, $* * * p \leq 0.001$ tively. Representative images of the indicated layers from two independent experiments are shown. Images for the NB and below NB layers are from the same embryo for each treatment, whereas the image for the neuronal layer is from a different embryo. Scale bars, $50 \mu \mathrm{m}$. Right two panels: Higher magnification images from the NB layer. Scale bars, $20 \mu \mathrm{m}$

(Zhang et al. 2012), its involvement in the radiation resistance of NBs cannot be ruled out.

In response to stress, stem cells can be lost with or without cell death. The loss of NBs at $3 \mathrm{~h}$ after IR did not appear to be caused by apoptotic cell death, as apoptotic markers were not detected (Fig. 7). Various cell death pathways have been described, in addition to apoptotic cell death (Galluzzi et al. 2018). Notably, p53-overexpression in larval brain NBs induces NB loss by necrosis but not apoptosis (Kuang et al. 2014). Recently, an alternative cell death pathway involving a DNase II-mediated parthanatos-like mechanism observed under pathological conditions has been reported in Drosophila and has been shown to be responsible for primordial germ cell death in embryos during development (TarayrahIbraheim et al. 2021). Whether there is a similar mechanism for embryonic NB loss after IR remains to be explored. In the absence of cell death, stem cells can differentiate prematurely and are subsequently lost in response to stress (Toussaint et al. 2002; Inomata et al. 2009). Results from intestinal stem cells using an in vitro colon cancer cell line and in vivo mouse model showed that endoplasmic reticulum stress can lead to a loss of stem cell markers without apoptosis, and that stressed stem cells are removed by differentiation (Heijmans et al. 2013). Similarly, we found that the stem cell markers Dpn and Klu were dysregulated (Fig. 5D) and NBspecific Insc promoter activity was undetectable at $3 \mathrm{~h}$ after 
IR (Fig. 5A). Moreover, the intensity of Pros staining and the number of neurons stained by Elav were significantly reduced at $3 \mathrm{~h}$ after IR (Fig. 8). Notably, expression of Prospero-related homeobox 1 (ProX1) related to the Drosophila pros decreases in mouse hippocampal neurons after irradiation (Wu et al. 2010). Although we found clues for defective neurogenesis after irradiation, further analysis is required to reveal the biological significance and the mechanism of phenotypic changes observed in this study.

Altogether, our work revealed the effect of IR exposure on embryonic NB and locomotor ability in adult survivors. We showed that a threshold dose of $3 \mathrm{~Gy}$ is required for the induction of cell death in the embryo, NB loss, and defective motor function in surviving adults. These results may shed light on the use of Drosophila embryos as a model in therapeutic interventions aimed at reducing the side effects of radiation therapy in pediatric brain tumors.

\section{Materials and methods}

\section{Drosophila strains}

All Drosophila strains were maintained at $25{ }^{\circ} \mathrm{C}$ on a standard food. Wild-type controls included $w^{1118}$ flies. Su(Z)12[3], Su(var)3-9[2], HDAC1[04556], PC[1], and p53[5A-1-4] were obtained from the Bloomington Drosophila Stock Centre, Indiana University (Bloomington, IN, USA). UAS-hid/reaper was a kind gift from Dr. J. Shim and Insc-Gal4, UAS-mCD8GFP/Cyo (Neumuller et al. 2011) was provided by Dr. J. Knoblich.

\section{Embryo collection and irradiation treatment}

Eggs were collected for $3 \mathrm{~h}$ from 3- to 5-day-old flies at $25{ }^{\circ} \mathrm{C}$ on molasses plates supplemented with a thin layer of freshly prepared yeast paste. Eggs were further developed for $4 \mathrm{~h}$ at $25^{\circ} \mathrm{C}$, and the resulting embryos at $4-7 \mathrm{~h}$ AEL were subjected to radiation treatment, unless otherwise stated. At least two plates per genotype or treatment were prepared for each experiment. One plate was irradiated in a $\mathrm{Cs}^{137}$ gamma-irradiator (Nordion Inc., Ontario, Canada) at the indicated doses, while the other plate was mock treated (0 Gy). After radiation treatment, plates were incubated at $25^{\circ} \mathrm{C}$ for a specified duration before further processing.

\section{Embryo staining}

Immunofluorescence staining of embryos was performed following the standard method (Patel 1994) with slight modifications. Briefly, embryos were dechorionated with $50 \%(\mathrm{v} / \mathrm{v})$ commercial bleach for $3 \mathrm{~min}$ and fixed for $20 \mathrm{~min}$ in a 1:1 mixture of $4 \%(\mathrm{v} / \mathrm{v})$ formaldehyde
(Sigma-Aldrich, St. Louis, MO, USA) in $1 \times$ phosphatebuffered saline (PBS; $137 \mathrm{mM} \mathrm{NaCl}, 2.7 \mathrm{mM} \mathrm{KCl}, 8 \mathrm{mM}$ $\mathrm{Na}_{2} \mathrm{HPO}_{4}$, and $2 \mathrm{mM} \mathrm{KH} \mathrm{PO}_{4}$ ) and heptane (SigmaAldrich) with rocking at $25^{\circ} \mathrm{C}$. After removing the lower fix layer, methanol (Samchun Chemicals, Pyeongtaek-si, Korea) was added. Embryos were then vortexed for $30 \mathrm{~s}$ and washed with methanol. Embryos were rehydrated in $0.1 \%$ PBT $(0.1 \%$ Triton-X 100 in $1 \times$ PBS $)$ and blocked with 5\% normal donkey serum (Jackson ImmunoResearch Inc., West Grove, PA, USA) in $0.1 \%$ PBT for $30 \mathrm{~min}$ at RT. Embryos were treated with primary antibodies at $4{ }^{\circ} \mathrm{C}$ overnight and washed 4-5 times with $0.1 \%$ PBT for $10 \mathrm{~min}$ each, followed by incubation with secondary antibodies for $2 \mathrm{~h}$ at RT. After washing with $0.1 \%$ PBT, the embryos were stained with $4^{\prime}, 6$-diamidino-2-phenylindole and mounted in $0.5 \% \mathrm{n}$-propyl gallate dissolved in glycerol.

The primary antibodies used in this study were against Deadpan (Abcam, Cambridge, UK), Klumpfuss (obtained from Dr. Y. Cai), cleaved Dcp-1 (Asp216) (Cell Signalling Technology, Danvers, MA, USA), GFP (Santa Cruz Biotechnology, Dallas, TX, USA), phospho-histone H3 Ser10 (PH3) (Millipore-Sigma, Burlington, MA, USA), Prospero MR1A (Developmental Studies Hybridoma Bank, DSHB, Iowa City, IA, USA), and Elav 7E8A10 (DSHB).

Secondary antibodies were purchased from Jackson ImmunoResearch Inc. and Molecular Probes (Waltham, MA, USA). Images were captured using an LSM 700 confocal laser scanning microscope (Carl Zeiss AG, Jena, Germany). For figures showing both the surface and NB layers, images were taken from the same embryo, unless otherwise stated.

Acridine orange/ethidium bromide (AO/EB) double labeling was performed as previously described (Sarkissian et al. 2014), except that $2.5 \mathrm{mg} / \mathrm{mL}$ EB was included in addition to $2.5 \mathrm{mg} / \mathrm{mL}$ AO. The TUNEL assay was performed as previously described (Arama and Steller 2006), except that digestion with proteinase $\mathrm{K}$ was reduced for $1 \mathrm{~min}$. For antibody and TUNEL co-labeling experiments, embryos were first subjected to immunofluorescence staining with antibodies as described above, followed by the TUNEL assay. FISH was performed on fixed embryos as previously described (Park et al. 2019). The RNA probe for hid in sense and anti-sense orientation was generated as previously described (Park et al. 2019).

\section{Climbing assay}

Locomotor ability was determined by a climbing assay on adult males, as previously described (Sudmeier et al. 2015). After eclosion, ten adult male flies derived from irradiated embryos were collected and cultured in vials for 5-6 days. Each group of flies was then transferred to 
a climbing apparatus made up of two empty plastic vials taped together at the open end. After a 1-min recovery, climbing pass rate was determined as the percentage of flies that successfully climbed past a $5 \mathrm{~cm}$ mark within $10 \mathrm{~s}$ after gently tapping them to the bottom. A total of five trials were performed for each group, with a 1-min recovery between trials.

\section{Quantitation and statistical analysis}

All quantitative analyses were performed on single confocal sections taken from the layer containing the maximum number of NBs. NBs were identified as cells that were stained with Deadpan, Klumpfuss, or Insc $>$ mCD8GFP. The proliferation of NBs was determined by counting the total and PH3-positive NBs from each embryo and expressed as the percentage of PH3-positive NBs per embryo. Statistical analysis was performed using a two-tailed unpaired Student's $t$ test. Differences were considered statistically significant at $p<0.05$.

Supplementary Information The online version contains supplementary material available at https://doi.org/10.1007/s13273-021-00212-y.

Acknowledgements This work was supported by the Basic Science Research Program through the National Research Foundation of Korea (NRF) funded by the Ministry of Education (NRF-2018R1D1A1B07042097).

Author contributions Y.-H.S. designed the experiments and supervised the project. R.W. performed the experiments and analyzed the data. Y.-H.S. and R.W. wrote and reviewed the manuscript.

\section{Declarations}

Conflict of interest Y.-H.S. declares no conflict of interest. R.W. declares no conflict of interest.

Ethical approval This article does not contain any studies with human participants or animals performed by any of the authors.

Open Access This article is licensed under a Creative Commons Attribution 4.0 International License, which permits use, sharing, adaptation, distribution and reproduction in any medium or format, as long as you give appropriate credit to the original author(s) and the source, provide a link to the Creative Commons licence, and indicate if changes were made. The images or other third party material in this article are included in the article's Creative Commons licence, unless indicated otherwise in a credit line to the material. If material is not included in the article's Creative Commons licence and your intended use is not permitted by statutory regulation or exceeds the permitted use, you will need to obtain permission directly from the copyright holder. To view a copy of this licence, visit http://creativecommons.org/licenses/by/4.0/.

\section{References}

Arama E, Steller H (2006) Detection of apoptosis by terminal deoxynucleotidyl transferase-mediated dUTP nick-end labeling and acridine orange in Drosophila embryos and adult male gonads. Nat Protoc 1:1725-1731

Galluzzi L et al (2018) Molecular mechanisms of cell death: recommendations of the Nomenclature Committee on Cell Death 2018. Cell Death Differ 25:486-541

Halme A et al (2010) Retinoids regulate a developmental checkpoint for tissue regeneration in Drosophila. Curr Biol 20:458-463

Harding K, White K (2018) Drosophila as a model for developmental biology: stem cell-fate decisions in the developing nervous system. J Dev Biol 6:25

Heijmans J et al (2013) ER stress causes rapid loss of intestinal epithelial stemness through activation of the unfolded protein response. Cell Rep 3:1128-1139

Homem CC, Knoblich JA (2012) Drosophila neuroblasts: a model for stem cell biology. Development 139:4297-4310

Inomata $\mathrm{K}$ et al (2009) Genotoxic stress abrogates renewal of melanocyte stem cells by triggering their differentiation. Cell 137:1088-1099

Kuang C et al (2014) A novel fizzy/Cdc20-dependent mechanism suppresses necrosis in neural stem cells. Development 141:1453-1464

Neumuller RA et al (2011) Genome-wide analysis of self-renewal in Drosophila neural stem cells by transgenic RNAi. Cell Stem Cell 8:580-593

Noguchi M et al (2020) Autophagy as a modulator of cell death machinery. Cell Death Dis 11:517

Park JH et al (2019) Role of p53 isoforms in the DNA damage response during Drosophila oogenesis. Sci Rep 9:11473

Patel NH (1994) Chapter 24. Imaging neuronal subsets and other cell types in whole-mount Drosophila embryos and larvae using antibody probes. Methods Cell Biol 44:445-487

Poodry CA, Woods DF (1990) Control of the developmental timer for Drosophila pupariation. Roux's Arch Dev Biol 199:219-227

Prokop A, Technau G (1991) The origin of postembryonic neuroblasts in ventral nerve cord of Drosophila melanogaster. Development 111:79-88

Ruiz de Almodóvar JM et al (1994) Dose-rate effect for DNA damage induced by ionizing radiation in human tumor cells. Radiat Res 138:S93-S96

Sarkissian T et al (2014) Detecting apoptosis in Drosophila tissues and cells. Methods 68:89-96

Southall TD, Brand AH (2009) Neural stem cell transcriptional networks highlight genes essential for nervous system development. EMBO J 28:3799-3807

Sudmeier LJ et al (2015) A Drosophila model to investigate the neurotoxic side effects of radiation exposure. Dis Model Mech 8:669-677

Tarayrah-Ibraheim L et al (2021) DNase II mediates a parthanatos-like developmental cell death pathway in Drosophila primordial germ cells. Nat Commun 12:2285

Toussaint $O$ et al (2002) Stress-induced premature senescence or stressinduced senescence-like phenotype: one in vivo reality, two possible definitions? ScientificWorldJournal 2:230-247

Urbach R, Technau GM (2003) Molecular markers for identified neuroblasts in the developing brain of Drosophila. Development 130:3621-3637

Wagle R, Song YH (2020) Ionizing radiation reduces larval brain size by inducing premature differentiation of Drosophila neural stem cells. Biochem Biophys Res Commun 523:555-560

Wu KL et al (2010) Loss of neuronal protein expression in mouse hippocampus after irradiation. J Neuropathol Exp Neurol 69:272-280 
Xing Y et al (2015) Tie-mediated signal from apoptotic cells protects stem cells in Drosophila melanogaster. Nat Commun 6:7058

Yasuda $\mathrm{T}$ et al (2006) Radiation-induced brain cell death can be observed in living medaka embryos. J Radiat Res 47:295-303

Zhang Y et al (2008) Epigenetic blocking of an enhancer region controls irradiation-induced proapoptotic gene expression in Drosophila embryos. Dev Cell 14:481-493

Zhang Q et al (2012) Autophagy activation: a novel mechanism of atorvastatin to protect mesenchymal stem cells from hypoxia and serum deprivation via AMP-activated protein kinase/mammalian target of rapamycin pathway. Stem Cells Dev 21:1321-1332

Zhao H et al (2019) Effects of different doses of X-ray irradiation on cell apoptosis, cell cycle, DNA damage repair and glycolysis in HeLa cells. Oncol Lett 17:42-54
Zhao W et al (2020) Effects of low-dose gamma-ray radiation on apoptosis and development of zebrafish embryo brain. Radiat Res 194:61-70

Publisher's Note Springer Nature remains neutral with regard to jurisdictional claims in published maps and institutional affiliations. 